\title{
Padina boryana, a brown alga from the Maldives: inhibition of a-MSH-stimulated melanogenesis via the activation of ERK in B16F10 cells
}

Thilina U. Jayawardena ${ }^{1}$, K. K. Asanka Sanjeewa ${ }^{1}$, Hyun-Soo Kim² ${ }^{2}$ Hyo Geun Lee ${ }^{1}$, Lei Wang ${ }^{1,3}$, Dae-Sung Lee ${ }^{2^{*}}$ and You-Jin Jeon ${ }^{1,3^{*}}$

\begin{abstract}
Background: The present study investigates the potent skin whitening ability of ethanol extract from the brown alga, Padina boryana (PBE) which was collected in the shores of Fulhadhoo Island, the Maldives, and its specific pathways of action. The effect of PBE which contains a rich amount of polyphenols was evaluated using B16F10 murine melanoma cells and provides insight to the underlying mechanisms with reference to the inhibition of melanin formation.

Methods: Melanin synthesis and cellular tyrosinase inhibition were assessed in the a-MSH-stimulated melanocytes. Melanogenic pathway-related protein expressions were investigated via Western blotting. ERK 42/44 was particularly examined considering its involvement in the melanogenic pathway. Further, RT-qPCR techniques were involved in gene expression analysis.

Results: PBE dose-dependently inhibited the cellular melanin synthesis and tyrosinase levels. Western blotting revealed the potential of PBE to downregulate microphthalmia-associated transcription factor (MITF), tyrosinase, and tyrosinaserelated protein-1 and protein-2 (TRP-1 and TRP-2). Moreover, results explained the phosphorylation of ERK was sustained via PBE and hence declined the ultimate melanin synthesis. Gene expression analysis reinforced the results obtained.
\end{abstract}

Conclusions: The study provides substantial evidence to express the potential of PBE to inhibit B16F10 melanoma cell melanin synthesis. Concisely, results suggest the ability of PBE to be involved in medicinal and cosmeceutical applications.

Keywords: Padina boryana, Brown alga, B16F10, Melanogenesis, ERK, Tyrosinase

\section{Introduction}

Melanin is a polymer synthesized in the melanosomes which are specialized cellular organelles. This is an indole derivative of 3,4-dihydroxyphenylalanine (DOPA). The process initiates with tyrosine and follows a series of oxidative steps (Ito and Wakamatsu 2003; Sarangarajan and Apte 2006). The outermost layer of the skin, keratinocytes, receives mature melanosomes. Melanin is important in

\footnotetext{
* Correspondence: daesung@mabik.re.kr; youjin2014@gmail.com

${ }^{2}$ National Marine Biodiversity Institute of Korea, Seocheon, Republic of Korea 'Department of Marine Life Sciences, Jeju National University, Jeju 690-756, Republic of Korea

Full list of author information is available at the end of the article
}

providing protection to the skin against DNA damage induced via UV radiation. The maximal energy absorption of melanin is in the UV range and is converted into different energy forms (Park et al. 2009). Even though melanin has protective properties, the accumulation of melanin due to UV irradiation leads to skin hyperpigmentation (Agar and Young 2005). Earlier studies have proven overaccumulation of melanin stimulating healthcare issues including freckles, age spots, and inflammatory disorders (Huang et al. 2016). Different factors determine the level of production of melanin including exposure to sunlight, dysfunctions in the thyroid gland, drug usage, and genetic

(c) The Author(s). 2020 Open Access This article is licensed under a Creative Commons Attribution 4.0 International License, which permits use, sharing, adaptation, distribution and reproduction in any medium or format, as long as you give appropriate credit to the original author(s) and the source, provide a link to the Creative Commons licence, and indicate if changes were made. The images or other third party material in this article are included in the article's Creative Commons licence, unless indicated otherwise in a credit line to the material. If material is not included in the article's Creative Commons licence and your intended use is not permitted by statutory regulation or exceeds the permitted use, you will need to obtain permission directly from the copyright holder. To view a copy of this licence, visit http://creativecommons.org/licenses/by/4.0/. 
background (Sanjeewa et al. 2016). Fair skin is preferred over dark skin in Asian countries. Skin whitening, lightening components that disturb the melanin production process, is possibly classified as cosmeceuticals (Boonme et al. 2009).

The synthesis of melanin occurs via the catalysis of the enzyme tyrosinase. Tyrosinase catalyzes the oxidation of tyrosine to hydroxylation of L-tyrosin to L-dihydroxyphenylalanine (L-DOPA). The reaction proceeds ahead in the Raper-mason pathway (Raper 1928). DOPA is subsequently oxidized into DOPA-quinone. The pathway is associated with further enzymes including tyrosinase-related protein (TRP-1 and TRP-2). Microphthalmia-associated transcription factor (MITF) which is an essential transcriptional factor regulating the transcription of the melanogenic pathway is linked with proteins such as TRP-1, TRP-2, and tyrosinase. The downregulation of the above ultimately leads to lower melanin production and could be regarded as ways of skin whitening (Bae et al. 2016). Recently, several studies have correlated the effect of extracellular signal-regulated kinase (ERK) on the melanogenic pathway. It is evident that phosphorylation of ERK inhibits the MITF proceeding to its next step hence downregulating the total melanin production (Yao et al. 2013).

Different components have been used in the industrial level to promote skin whitening, including arbutin, kojic acid, and azelaic acid as tyrosinase inhibitors (Huang et al. 2016). Some of the components such as arbutin have been restricted due to its side effects such as imperishable depigmentation. Due to this reason, the interest in natural products to fulfill the purpose has risen.

Marine algae are exposed to external extreme factors throughout their life span. These include high oxygen concentrations, intense light, stress, and UV radiation. The effect of the above factors is successfully overcome by the seaweeds due to its rich sources of bioactive components (Heo et al. 2010). Padina boryana, a brown alga species from the coastal lines of the Maldives, is not explored for its bioactive properties to a larger extent. Components purified from brown algae have earlier been assessed on the inhibition of $\alpha$-melanocyte-stimulating hormone ( $\alpha-\mathrm{MSH})$ stimulated melanogenesis (Kim et al. 2013). The given facts such as low cost, less environmental pollution, and lower toxicity have enhanced the implementation of ethanolassisted extraction of plant materials to isolate bioactive metabolites. (Wijesinghe and Jeon 2012). Hence, with the support of the above evidence, this study implements ethanol extraction of P. boryana. According to the best of our knowledge, this is the first report associated with melanogenesis inhibition activity of $P$. boryana ethanol extract (PBE). The present study aims to evaluate the potential of PBE to inhibit melanogenesis. Further, the study was extended to assess the involvement of $\mathrm{PBE}$ in specific melanogenic pathway mediator proteins in order to confirm its mechanism of action.

\section{Methods \\ Materials}

Cell media, Dulbecco's modified Eagle's medium (DMEM), and its supplementary material fetal bovine serum (FBS) and penicillin were obtained from Invitrogen-Gibco (Grand Island, NY, USA). The murine melanoma cell line (B16F10) was purchased from ATCC (American Type Culture Collection, Manassas, VA, USA). 3-(4,5-Dimethylthiazol-2-yl)-2,5-diphenyltetrazolium bromide (MTT), alpha-melanocyte-stimulating hormone $(\alpha-\mathrm{MSH})$, and LDOPA were purchased from Sigma-Aldrich (St. Louis, MO, USA). Primary antibodies used in the study, namely tyrosinase, TRP1, TRP-2, MITF, and ERK 1/2, were purchased from Santa Cruz Biotechnology (Santa Cruz, CA, USA). Anti-mouse and anti-rabbit IgG were purchased from Cell Signaling Technology (Beverly, MA, USA). cDNA kits purchased from TaKaRa Japan were used in the experiments. All the primers used in this study were purchased from Bioneer, Seoul, South Korea. Unless otherwise specified, all the reagents used in the experiments were of analytical grade and were purchased from Sigma-Aldrich Chemical Co. (St. Louis, MO, USA).

\section{Extraction from Padina boryana and compositional analysis}

$P$. boryana brown alga species were collected from the shores of Fulhadhoo Island, the Maldives, in August 2018. The sample was immediately washed with running water and then lyophilized and ground into powder. Sample identification was assisted by Jeju Biodiversity Research Institute. A 70\% ethanol extraction was carried out with $50 \mathrm{~g}$ of sample powder and was repeated the same three times. The supernatant was filtered using vacuum filtration. Rotary evaporation was used to evaporate the solvent and the dry sample was named PBE. A stock sample solution was prepared by dissolving PBE in dimethyl sulfoxide (DMSO). Working sample concentrations were subsequently prepared using DMEM (Heo et al. 2010).

The content of the ethanol extract was assessed using appropriate methods. Accordingly, polyphenol content was measured using the Folin-Ciocalteu method (Ochanda et al. 2015). Polysaccharide content was estimated using the microplate method described by Masuko et al. (2005). BCA protein assay kit was used to measure the protein content following the standard protocol (Herath et al. 2019). Ash content of the crude sample was measured using the dry ashing method following the procedure described as AOAC 1998 (Kim et al. 2018). Moisture content was assessed via the oven-drying method at $105{ }^{\circ} \mathrm{C}$. Further, the Soxhlet method with diethyl ether as the solvent was implemented 
to evaluate the lipid content of the crude sample (Chandler and Dodds 1983).

\section{Cell line maintenance}

The growth media (DMEM) supplemented with 10\% heat-inactivated FBS and 1\% antibiotic were used to culture murine melanoma cells (B16F10). A controlled environment with a humidified atmosphere including $5 \% \mathrm{CO}_{2}$ and $37{ }^{\circ} \mathrm{C}$ temperature was used to maintain the cell lines. The cells were periodically subcultured and were used for experiments in its exponential growth phase.

\section{Cell viability measurement}

The cellular cytotoxicity against PBE was examined via the MTT colorimetric assay (Mosmann 1983). Cells were seeded with a cell concentration of $2 \times 10^{5}$ cells $/ \mathrm{mL}$ in a 24-well plate. Given a 16-h incubation period, the cells were then treated with $\operatorname{PBE}(25,50,100$, and $200 \mu \mathrm{g}$ $\mathrm{mL}^{-1}$ ), and incubation was continued for $72 \mathrm{~h}$. The viability percentage was calculated referring to the control well. Similarly, B16F10 cells were stimulated under $\alpha-\mathrm{MSH}$ and samples were treated to evaluate the cytotoxicity.

\section{Cellular melanin content measurement}

The cells were seeded as previously, then stimulated with $\alpha-\mathrm{MSH}(50 \mathrm{nM})$, and were co-treated with different concentrations of $\operatorname{PBE}\left(25,50\right.$, and $\left.100 \mu \mathrm{g} \mathrm{mL}^{-1}\right)$. The incubation was continued for $72-\mathrm{h}$ period. Arbutin $(100 \mu \mathrm{M})$ was used as the commercial melanin inhibitor to compare the results. The cells were then harvested and washed with ice-cold PBS. In order to solubilize the melanin, this was incubated at $80{ }^{\circ} \mathrm{C}$ for $1 \mathrm{~h}$ in $1 \mathrm{~mL}$ of $1 \mathrm{~N} \mathrm{NaOH} / 10 \%$ DMSO solution. The optical density was measured at 450 nm range (Yoon et al. 2010; Wang et al. 2019).

\section{Assessment of cellular tyrosinase activity}

To measure the cellular tyrosinase activity, we followed the method described by Kim et al. (2007) and Tomita et al. (1992) with slight modifications. In brief, the cells were seeded in a similar manner as previously. $\alpha-\mathrm{MSH}(50$ $\mathrm{nM}$ ) and PBE were co-treated after a 16-h incubation period and then continued for $72 \mathrm{~h}$. Similarly, the cells were harvested, washed with ice-cold PBS, and lysed using PBS containing 1\% Triton X-100. The cell lysate supernatants were collected after centrifugation $(10,000 \times g$ for 10 $\mathrm{min})$. Proteins were quantified and normalized. A $90-\mu \mathrm{L}$ portion of each cell extract (which now contains equal protein levels) was incubated with $10 \mu \mathrm{L}$ of L-DOPA at 37 ${ }^{\circ} \mathrm{C}$ for $1 \mathrm{~h}$. The resulting dopachrome was observed under $405 \mathrm{~nm}$ optical density.

\section{Western blot analysis}

In order to determine the expression of melanogenesisrelated proteins such as MITF, tyrosinase, TRP-1, and
TRP-2, the Western blotting was performed. Cells were seeded and stimulated with $\alpha-\mathrm{MSH}$ and co-treated with PBE. Cells were harvested and washed with ice-cold PBS and lysed. Then the protein content of each was measured via Pierce ${ }^{\mathrm{TM}}$ BCA Protein Assay Kit and normalized. SDSPAGE was conducted and transferred to nitrocellulose membranes. These were successively blocked with skim milk and incubated with relevant primary antibodies. The membranes were then incubated in the HRP-conjugated anti-mouse/anti-rabbit IgG secondary antibodies. Finally, the bands were visualized by enhancing them with chemiluminescence (ECL) reagent (Amersham, Arlington Heights, IL, USA) and photographed (FUSION SOLO Vilber Lourmat system). ImageJ program was assisted in the band intensity quantification (Sanjeewa et al. 2018; Jayawardena et al. 2018).

The effect of ERK/MAPKs was assessed using specific inhibitors. $\alpha-\mathrm{MSH}$ and samples were added in the presence and absence of ERK inhibitor (PD98059). The Western blotting followed the same protocol as described above. Similarly, the expression of tyrosinase was also assessed with the presence and absence of PD98059.

\section{Extraction of RNA and CDNA synthesis}

Tri-Reagent $^{\text {TM }}$ (Sigma-Aldrich, St. Louis, MO, USA) was used to extract total RNA from the harvested B16F10 cells. The purity and the concentration of extracted RNA were determined using a $\mu$ Drop Plate (Thermo Scientific, IL, Rockford, USA). RNA was then diluted $\left(1 \mu \mathrm{g} \mu \mathrm{L}^{-1}\right)$ with the purpose of synthesizing cDNA. cDNA was synthesized using the Prime Script ${ }^{\mathrm{m}} \mathrm{cDNA}$ synthesize kit (TaKaRa BIO INC, Japan) following the manufacturers' instructions and stored at $-80{ }^{\circ} \mathrm{C}$.

\section{Quantitative real-time PCR analysis}

The prepared cDNA was used to assess the mRNA expression levels of tyrosinase and MITF. SYBR Green quantitative real-time PCR technique was used with the assistance of a Thermal Cycler Dice Real-Time System (TaKaRa, Japan). Primers used in the experiment were tyrosine sense 5'-GGCCAGCTTTCAGGCAGAGGT-3', antisense $5^{\prime}$-TGGTGCTTCATGGGCAAAATC-3'; and MITF sense 5' -GTATGAACACGCACTCTCGA-3', antisense 5'-CGAACGTATTTGCCATTTGC-3'. GAPDH was used as the housekeeping gene; sense $5^{\prime}$-AAGGGT CATCATCTCTGCCC-3', antisense 5'-GTGATGGCAT GGACTGTGGT-3'. The primers were purchased from Bioneer, Seoul, South Korea. For the amplification process, the reaction was carried out using $3 \mu \mathrm{L}$ of cDNA, $5 \mu \mathrm{L}$ of $2 \times$ TaKaRa ExTaq $^{\text {Tm }}$ SYBR premix, $0.4 \mu \mathrm{L}$ each of the forward and reverse primers $(10 \mu \mathrm{M})$, and $1.2 \mu \mathrm{L}$ $\mathrm{ddH}_{2} \mathrm{O}$. The total reaction mixture contained $10 \mu \mathrm{L}$. The thermal profile used in the experiment is as follows, step 1: 1 cycle at $95{ }^{\circ} \mathrm{C}$ for $10 \mathrm{~s}$; step 2: 45 cycles at $95^{\circ} \mathrm{C}$ for 5 
s; step 3: $55^{\circ} \mathrm{C}$ for $10 \mathrm{~s}$; step $4: 72{ }^{\circ} \mathrm{C}$ for $20 \mathrm{~s}$; step $5: 95{ }^{\circ} \mathrm{C}$ for $15 \mathrm{~s}$; step 6: $55^{\circ} \mathrm{C}$ for $30 \mathrm{~s}$; and step $7: 95{ }^{\circ} \mathrm{C}$ for $15 \mathrm{~s}$. GAPDH was used as the internal reference standard. The analysis of relative expression was conducted using the method described by Livak and Schmittgen (2001).

\section{Statistical analysis}

All experiments were triplicated. Data are represented as the mean \pm standard deviation. IBM SPSS with one-way ANOVA was used in the statistical analysis process. $p$ values less than $0.05(p<0.05)$ were considered significant.

\section{Results}

\section{Compositional analysis}

The analysis results revealed that the crude sample was composed of a higher proportion of polysaccharide and protein $(57.87 \pm 0.63 \%$ and $16.36 \pm 0.32 \%)$. The lipid content was reported to be $1.03 \pm 0.25 \%$ while ash and moisture contents were $14.14 \pm 0.72 \%$ and $6.2 \pm 0.54 \%$. The ethanol extract yield was $4.8 \%$, while the total polyphenol was estimated as $8.84 \pm 0.23 \%$. The total polysaccharide content and proteins were reduced to $1.26 \pm$ $0.46 \%$ and $1.31 \pm 0.18 \%$ in ethanol extract.

\section{Cytotoxicity of PBE on melanoma cells}

The cytotoxic effect of the sample (PBE) against murine melanoma cells was first measured. A range of concentrations of PBE was used $\left(25,50,100\right.$, and $\left.200 \mu \mathrm{g} \mathrm{mL}{ }^{-1}\right)$. PBE did not exhibit significant cytotoxicity against melanoma cells in the $25-100 \mu \mathrm{g} \mathrm{mL}^{-1}$ range and subsequent experiments were planned accordingly (Fig. 1a). The melanoma cells which were co-treated with $\alpha-\mathrm{MSH}$ and PBE did not exhibit any significant toxicity. Results revealed that either $\alpha-\mathrm{MSH}$ or PBE in the given range of concentrations does not affect on the cell death of the murine melanoma cells (Fig. 1b).
Effect of PBE on melanin synthesis and tyrosinase activity in a-MSH-stimulated melanoma cells

The potential of PBE to inhibit the intracellular melanin production and the activity of tyrosinase in the presence of $\alpha-\mathrm{MSH}$ was evaluated. PBE successfully downregulated the cellular melanin content compared to the $\alpha-\mathrm{MSH}$ treated group (Fig. 2a). A similar trend was observed in the tyrosinase activity. $\alpha-\mathrm{MSH}$ induced cellular tyrosinase activity, whereas PBE gradually downregulated it (Fig. 2b). In both experiments, arbutin was used to compare the results. In combination, these results suggest that PBE is a potent treatment in downregulating the cellular tyrosinase activity hence melanin synthesis in melanoma cells.

\section{Effect of PBE on the expression of ERK-associated proteins in a-MSH-induced melanoma cells}

As it is evident, the ability of PBE to inhibit the melanin and tyrosinase activity, further experiments were carried out to elucidate its mechanism. Three selected enzymes (TRP-1, TRP-2, and tyrosinase) in the melanogenic pathway were evaluated. PBE dose-dependently reduced the expression of the three enzymes. MITF is a melanocytespecific transcription factor and regulates the expression of these three enzymes. The influence of PBE was examined on MITF expression as well (Fig. 3a, b). The observed results confirm that PBE successfully inhibits the MITF expression in B16F10 cells.

\section{Effect of PBE on melanogenesis-related protein expression}

The gene expression was analyzed using quantitative realtime PCR (qPCR) techniques. It was observed that the stimulation of $\alpha-\mathrm{MSH}$ increases the expression of tyrosinase and MITF, whereas treatment with PBE downregulates it. Furthermore, the ERK inhibitor (PD98059) involvement exhibited the expression levels grow up (Fig. 3c, d). This verifies the results of previous experiments conducted using Western blotting.

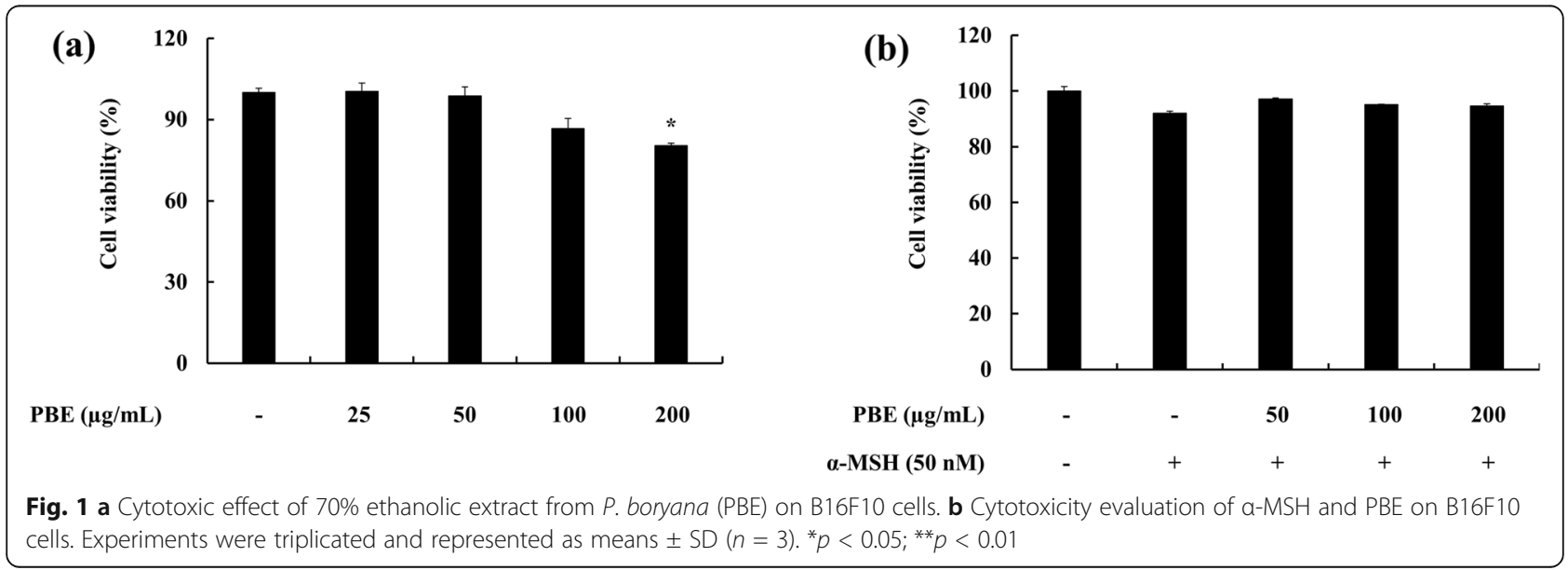




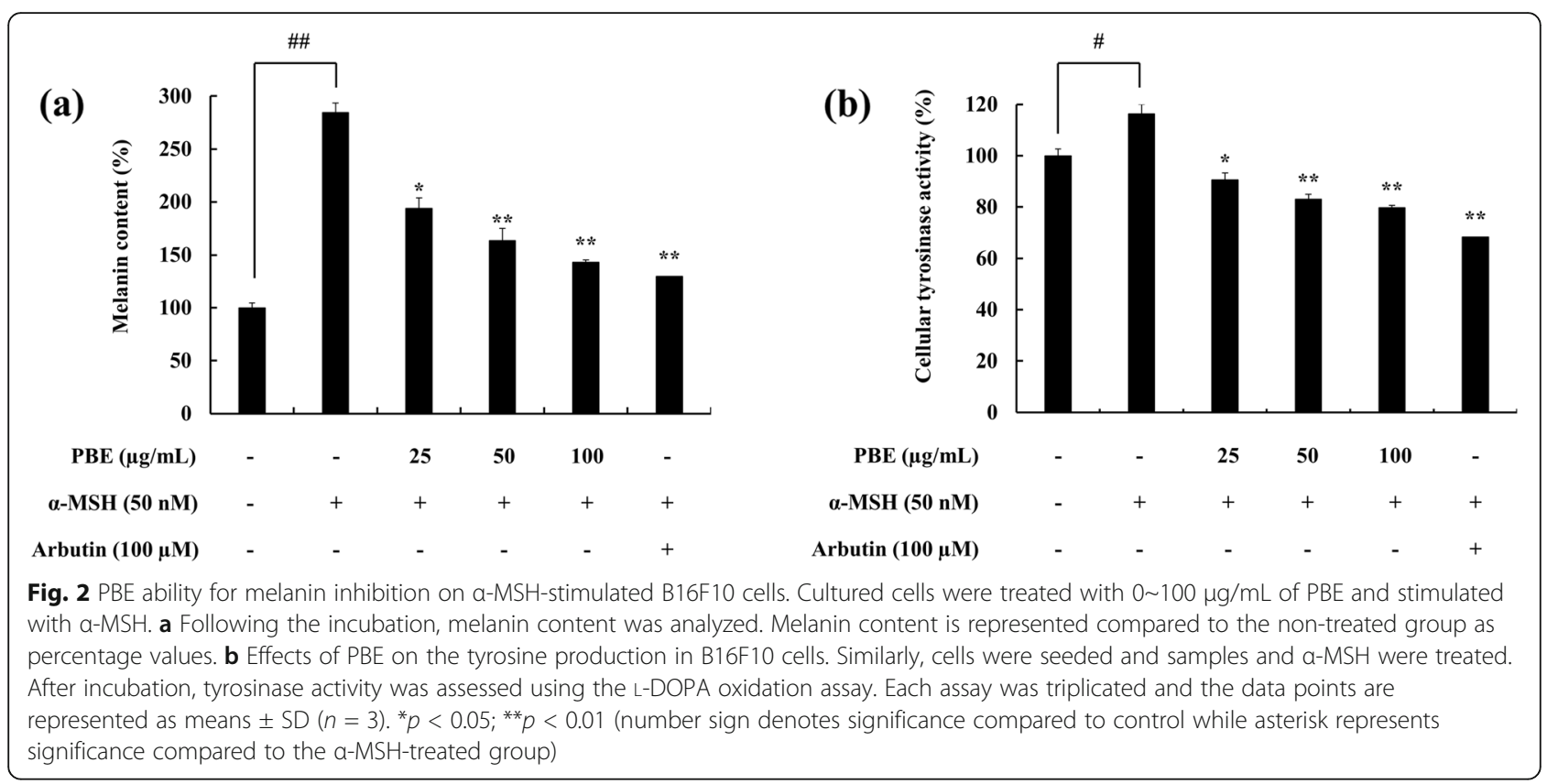

Effect of PBE on MAPK-associated ERK protein expression The effect of ERK on the melanogenesis process was assessed via Western blotting. The results show that in the presence of PBE under $\alpha$-MSH-stimulated conditions, ERK phosphorylation is enhanced. With the addition of ERK inhibitor (PD98059), the ERK phosphorylation is decreased (Fig. 4a, b). Furthermore, the tyrosinase protein expression which is decreased with the treatment of PBE in $\alpha$-MSH-induced melanocytes has been recovered in the presence of ERK inhibitor (Fig. 4c, d). These results suggest the potential of PBE to inhibit the melanogenesis process. It is evident to occur via ERK involved mitogen-activated protein kinase (MAPK) pathway in $\alpha$-MSH-stimulated B16F10 cells.

\section{Discussion}

The Asian cosmetic market has a high demand for skin whitening agents. The skin tone of the Asians is brown; thus, they prefer a change into a much fair skin tone (Sanjeewa et al. 2016). Melanin content in the skin is responsible for the darker skin. This plays an important role in protecting the skin from detrimental effects such as UV radiation exposure and in scavenging toxic compounds. Melanin is produced via tyrosinase acting on L-tyrosin hence with the production of L-DOPA (3-4-dihydroxyphenylalanine). L-DOPA is then oxidized by dopa oxidase to produce melanin (Solano et al. 2006; Martínez-Esparza et al. 1998). Thus, the inhibition of melanin synthesis via incorporating tyrosinase inhibitors is much familiar in the cosmeceutical market. The synthetic commercial products mostly use hydroquinone and mercury to achieve this, but undesirable side effects are possible (Kim et al. 2013). Due to this reason, recently, the research interest toward natural whitening agents has risen among the scientific community. Several times, the natural plant extracts' effect on the tyrosinase inhibition and hence melanin inhibition has been reported (Park et al. 2011; Arung et al. 2011).

The current study was focused on the bioactive properties of P. boryana $70 \%$ ethanol extract. Among different kinds of extraction processes, ethanol extract is highly recommended due to its effectiveness and ease of implementation in industrial backgrounds over other extraction methods (Wijesinghe and Jeon 2012). Seaweeds are a sustainable source of bioactive-rich compounds possessing diverse functional properties (Kim et al. 2018). These include polyphenols, polysaccharides, fatty acids, sterols, proteins, and several other components that enable them to be utilized in the development of functional ingredients in the cosmeceutical and nutraceutical industries. PBE contains a higher portion $(8.84 \%)$ of polyphenols, an active, large, and diverse class of secondary metabolites in the seaweeds. Polyphenols were reported to possess vital biological functionalities such as anti-oxidant (Shibata et al. 2007), antiinflammatory (Lee 2010), anti-hypertensive (Jung et al. 2006), and anti-melanogenesis activities (Kim et al. 2013). The activity of PBE is anticipated to be influenced through the polyphenol content. In the study, arbutin was used as the commercial active ingredient for skin whitening to compare the results with. In Northeast Asia, both kojic acid and arbutin are used in cosmetics. Arbutin is glycosylated hydroquinone from the bearberry plant and was reported to be used as a cure for hyperpigmentation disorder (Bae et al. 2016; Nishimura et al. 1995). 


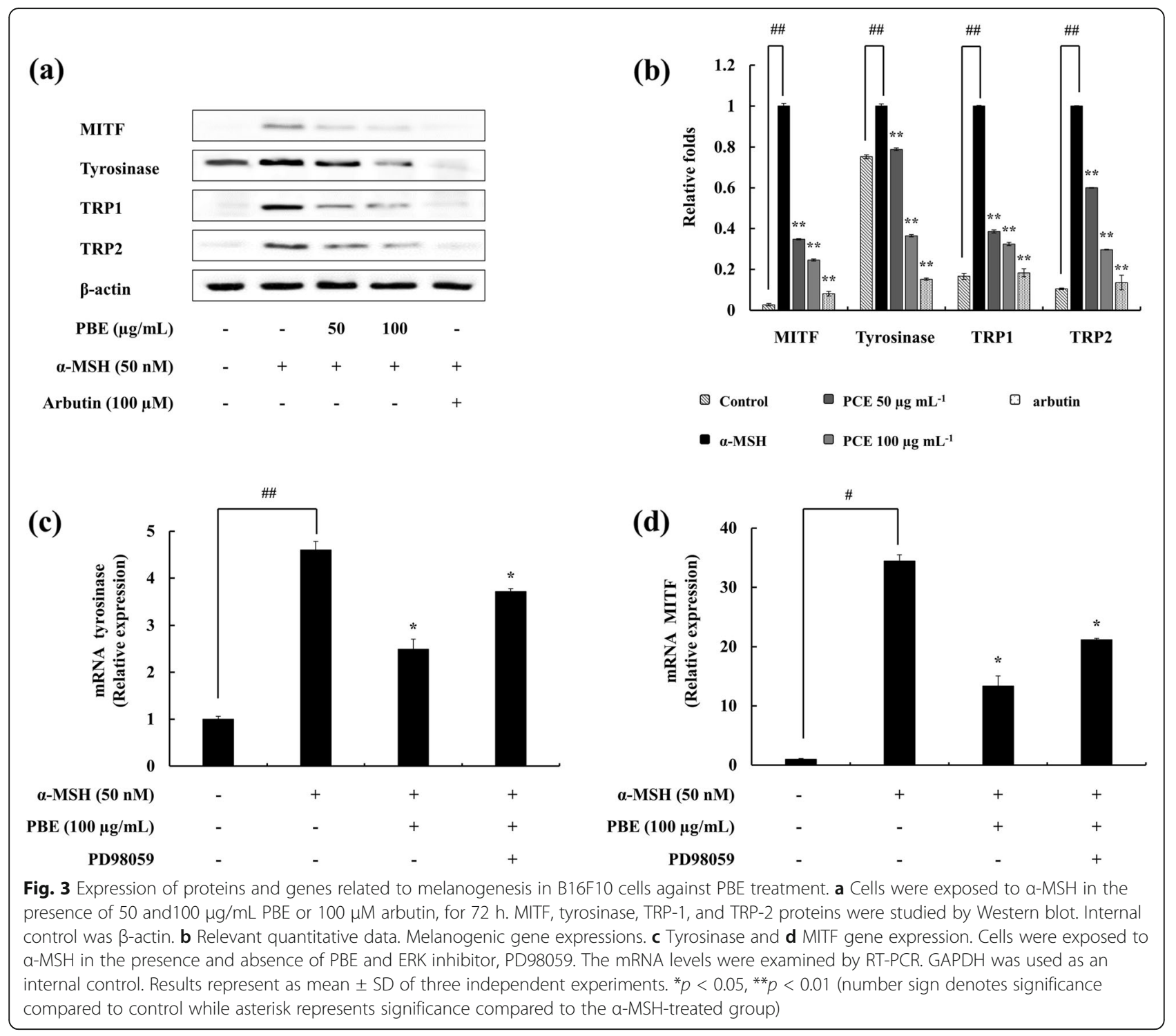

In the studies relevant to skin whitening, the murine melanoma cell line B16F10 is used. This cell is capable of synthesizing melanin and tyrosinase under stimulated conditions via $\alpha-\mathrm{MSH}$ (Chan et al. 2011). Initially, the toxic effect of the sample PBE was evaluated on the B16F10 cell line. Significant toxicity was not observed in the $25-100 \mu \mathrm{g} \mathrm{mL}^{-1}$ range. Hence, the researchers moved to the next step of examining the melanin and tyrosinase inhibitory properties of PBE. In the $\alpha-\mathrm{MSH}-$ stimulated B16F10 cells, the melanin content was downregulated dose-dependently, as well as the tyrosinase content with the pre-treatment of PBE. These results suggest the effect of $\mathrm{PBE}$ on inhibiting the activity of tyrosinase ultimately lowering the melanin content. In order to further investigate the melanogenic pathway, the study was extended to the transcription factor MITF level. MITF is an essential regulator in melanin synthesis besides the life and differentiation of melanocytes. It is involved in diverse cellular processes such as proliferation and stress mediation (Vachtenheim and Borovanský 2010). TRP-1 and TRP-2 are important enzymes which catalyze the melanin production. MITF induces the expression of the melanogenic pathway-related genes such as tyrosinase, TRP-1, and TRP-2 (Vachtenheim et al. 2001; Chan et al. 2011). The results suggest an upregulation of the particular proteins with $\alpha-\mathrm{MSH}$ stimulation and a successful downregulation with the treatment of PBE.

The MAPK-associated ERK is incorporated in the melanogenic pathway. The phosphorylation of ERK inhibits the expression of MITF in melanocytes (Bae et al. 2016). Earlier reports indicated phosphorylated ERK inhibiting the MITF phosphorylation (Kim et al. 2002; Vachtenheim and Borovanský 2010). The effect of ERK was analyzed 


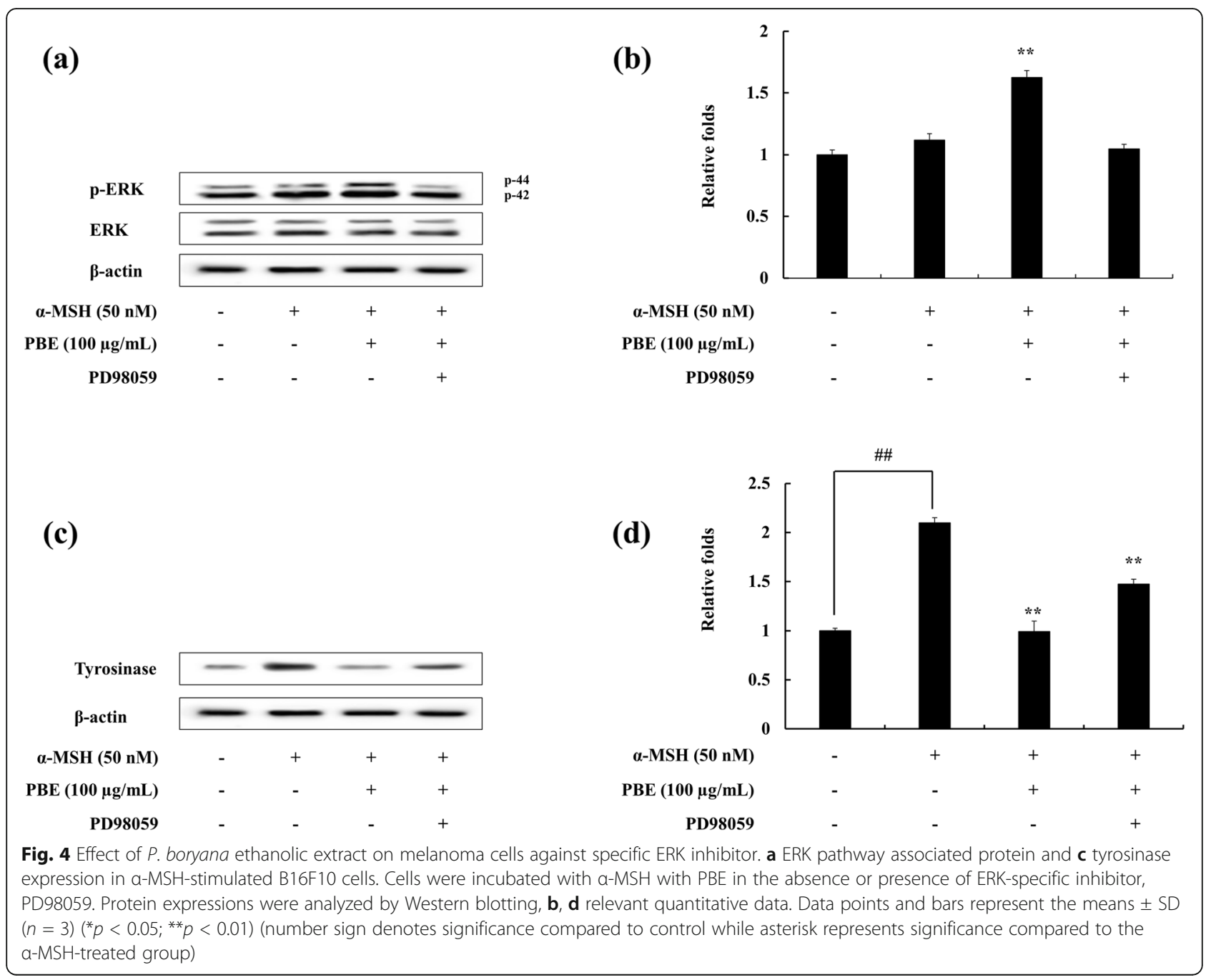

using Western blotting. It was evident that the presence of $\mathrm{PBE}$ in $\alpha-\mathrm{MSH}$ stimulated melanocytes' inclined expression of the phosphorylated form of ERK. Hence, the addition of the ERK inhibitor downregulated the phosphorylation of ERK. This confirms that the effect of PBE is mediated via the ERK of the MAPK pathway. Preliminary experiments supported the fact that PBE has the potential to inhibit the activity of tyrosinase. The effect of ERK on the production of tyrosinase was also experimented using ERK-specific inhibitors via Western blotting. The results revealed that in the presence of PD98059, tyrosinase levels were upregulated. These data are further supported by the gene expression analysis of tyrosinase and MITF in the presence of PD98059 (ERK inhibitor). MITF which is downregulated by the potential of PBE was inversed via the ERK inhibitor, supporting the fact that PBE is mediated via the ERK signals in the MAPK pathway. Similar research has been conducted using pure compounds as well as extracts of seaweed. Kim et al. (2013) investigated the potential of octaphlorethol A isolated from Isige foliacea to inhibit the melanogenesis via the ERK pathway in melanoma cells. The ethanol extract of soft coral Dedronephtya putteri was investigated in detail by Sanjeewa et al. (2018), for its potential to inhibit melanin synthesis in melanoma cells via the ERK pathway. In this study, therefore, it is revealed that PBE inhibits the synthesis of melanin by suppressing tyrosinase production via promoting ERK phosphorylation-associated MAPK pathway.

\section{Conclusions}

The present study reveals the potential of PBE which contains rich amounts of polyphenol to downregulate the melanin synthesis via inhibiting the tyrosinase activity in melanoma cells. The mediation involves inhibition of tyrosinase production-related enzyme inhibition (TRP-1 and TRP-2). MITF which is a central transcription factor in the melanin synthesis pathway was successfully inhibited via the activity of PBE. Further studies reinforced that the activity of PBE is mediated via the MAPK pathway, specifically ERK signaling cascade. Hence, PBE is a potential 
candidate in the pharmaceutical industry to be implemented as a skin whitening and lightening component in cosmetics. However, further studies involving the identity of active polyphenols and in vivo conditions should be applied before human consumption.

\section{Abbreviations}

DMEM: Dulbecco's modified Eagle's medium; ERK: Extracellular signalregulated kinase; FBS: Fetal bovine serum; L-DOPA: Hydroxylation of L-tyrosin to L-dihydroxyphenylalanine; MAPK: Mitogen-activated protein kinase; MITF: Microphthalmia-associated transcription factor; MTT: 3-(4, 5Dimethylthiazol-2-yl)-2,5-diphenyltetrazolium bromide; PBE: Padina boryana 70\% ethanol extract; PD98059: 2-(2-Amino-3-methoxyphenyl)-4H-1benzopyran-4-one; TRP-1: Tyrosinase-related protein-1; TRP-2: Tyrosinaserelated protein-2; a-MSH: a-Melanocyte-stimulating hormone

\section{Acknowledgements}

The authors extend their gratitude to the Ministry of Oceans and Fisheries, Korea, with regard to the support of this study.

\section{Authors' contributions}

YJJ, DSL, and TUJ conceived and designed the experiments. TUJ and KKAS performed the experiments. TUJ and KKAS analyzed the data. KKAS, HSK, $H G L$, and LW contributed the reagents/materials/analysis tools. TUJ wrote the paper. The authors read and approved the final manuscript.

\section{Funding}

This research was financially supported by a grant from the "Marine Biotechnology program-20170488," funded by the Ministry of Oceans and Fisheries, Korea.

\section{Availability of data and materials}

The data sets generated and/or analyzed during the current study are available from the corresponding author on a reasonable request.

\section{Ethics approval and consent to participate}

Not applicable

\section{Consent for publication}

Not applicable

\section{Competing interests}

The authors declare that they have no competing interests.

\section{Author details}

'Department of Marine Life Sciences, Jeju National University, Jeju 690-756, Republic of Korea. ${ }^{2}$ National Marine Biodiversity Institute of Korea, Seocheon, Republic of Korea. ${ }^{3}$ Marine Science Institute, Jeju National University, Jeju, Jeju Self-Governing Province 63333, Republic of Korea.

\section{Received: 6 February 2020 Accepted: 28 February 2020}

\section{Published online: 26 March 2020}

\section{References}

Agar N, Young AR. Melanogenesis: a photoprotective response to DNA damage? Mutat Res. 2005;571:121-32. https://doi.org/10.1016/j.mrfmmm.2004.11.016.

Arung ET, Furuta S, Ishikawa H, Kusuma IW, Shimizu K, Kondo R. Antimelanogenesis properties of quercetin-and its derivative-rich extract from Allium cepa. Food chemistry. 2011;124:1024-8. https://doi.org/10.1016/j. foodchem.2010.07.067.

Bae J-S, Han M, Yao C, Chung JH. Chaetocin inhibits IBMX-induced melanogenesis in B16F10 mouse melanoma cells through activation of ERK Chemico-biological interactions. 2016;245:66-71. https://doi.org/10.1016/j.cbi. 2015.12.021.

Boonme P, Junyaprasert VB, Suksawad N, Songkro S. Microemulsions and nanoemulsions: novel vehicles for whitening cosmeceuticals. J Biomed Nanotechnol. 2009:5:373-83. https://doi.org/10.1166/jbn.2009.1046.

Chan YY, Kim KH, Cheah SH. Inhibitory effects of Sargassum polycystum on tyrosinase activity and melanin formation in B16F10 murine melanoma cells. J Ethnopharmacol. 2011;137:1183-8. https://doi.org/10.1016/j.jep.2011.07.050.
Chandler SF, Dodds JH. The effect of phosphate, nitrogen and sucrose on the production of phenolics and solasodine in callus cultures of Solanum laciniatum. Plant Cell Rep. 1983;2:205-8. https://doi.org/10.1007/BF00270105.

Heo SJ, Yoon WJ, Kim KN, Ahn GN, Kang SM, Kang DH, Affan A, Oh C, Jung WK, Jeon YJ. Evaluation of anti-inflammatory effect of fucoxanthin isolated from brown algae in lipopolysaccharide-stimulated RAW 264.7 macrophages. Food Chem Toxicol. 2010;48:2045-51. https://doi.org/10.1016/j.fct.2010.05.003.

Herath K, Cho J, Kim A, Kim HS, Han EJ, Kim HJ, Kim MS, Ahn G, Jeon YJ, Jee Y. Differential modulation of immune response and cytokine profiles of Sargassum horneri ethanol extract in murine spleen with or without Concanavalin A stimulation. Biomed Pharmacother. 2019;110:930-42. https:// doi.org/10.1016/j.biopha.2018.12.001.

Huang H-C, Liao C-C, Peng C-C, Lim J-M, Siao J-H, Wei C-M, Chen C-C, Wu C-S, Chang T-M. Dihydromyricetin from Ampelopsis grossedentata inhibits melanogenesis through down-regulation of MAPK, PKA and PKC signaling pathways. Chem Biol Interact. 2016;258:166-74. https://doi.org/10.1016/j.cbi.2016.08.023.

Ito S. Wakamatsu K. Quantitative analysis of eumelanin and pheomelanin in humans, mice, and other animals: a comparative review. Pigment Cell Res. 2003:16:523-31. https://doi.org/10.1034/j.1600-0749.2003.00072.x.

Jayawardena TU, Asanka Sanjeewa KK, Shanura Fernando IP, Ryu BM, Kang MC, Jee $Y$, Lee WW, Jeon YJ. Sargassum horneri (Turner) C. Agardh ethanol extract inhibits the fine dust inflammation response via activating $\mathrm{Nrf} / \mathrm{HO}-1$ signaling in RAW 264.7 cells. BMC Complement Altern Med. 2018;18:249. doi: https://doi.org/10.1186/s12906-018-2314-6.

Jung HA, Hyun SK, Kim HR, Choi JS. Angiotensin-converting enzyme I inhibitory activity of phlorotannins from Ecklonia stolonifera. Fisheries Science. 2006;72: 1292-9. https://doi.org/10.1111/j.1444-2906.2006.01288.x.

Kim DS, Jeong YM, Park IK, Hahn HG, Lee HK, Kwon SB, Jeong JH, Yang SJ, Sohn UD, Park KC. A new 2-imino-1,3-thiazoline derivative, KHG22394, inhibits melanin synthesis in mouse B16 melanoma cells. Biol Pharm Bull. 2007;30: 180-3. https://doi.org/10.1248/bpb.30.180.

Kim DS, Kim SY, Chung JH, Kim KH, Eun HC, Park KC. Delayed ERK activation by ceramide reduces melanin synthesis in human melanocytes. Cell Signal. 2002;14:779-85. https://doi.org/10.1016/s0898-6568(02)00024-4.

Kim H-S, Sanjeewa K, Fernando I, Ryu B, Yang H-W, Ahn G, Kang MC, Heo S-J, Je J-G, Jeon Y-J. A comparative study of Sargassum horneri Korea and China strains collected along the coast of Jeju Island South Korea: its components and bioactive properties. Algae. 2018;33:341-9. https://doi.org/10.4490/algae. 2018.33.11.15.

Kim KN, Yang HM, Kang SM, Kim D, Ahn G, Jeon YJ. Octaphlorethol A isolated from Ishige foliacea inhibits alpha-MSH-stimulated induced melanogenesis via ERK pathway in B16F10 melanoma cells. Food Chem Toxicol. 2013;59: 521-6. https://doi.org/10.1016/j.fct.2013.06.031.

Lee $\mathrm{S}$. Anti-inflammatory mechanisms of phlorotannins derived from Eisenia bicyclis and their inhibitory effects on matrix metalloproteinases. Busan, South Korea: Pukyong National University; 2010.

Livak KJ, Schmittgen TD. Analysis of relative gene expression data using real-time quantitative PCR and the $2-\Delta \Delta C T$ method. methods. 2001;25:402-408. doi: https://doi.org/10.1006/meth.2001.1262.

Martínez-Esparza M, Jiménez-Cervantes C, Solano F, Lozano JA, García-Borrón JC. Mechanisms of melanogenesis inhibition by tumor necrosis factor-a in B16/ F10 mouse melanoma cells. Eur J Biochem. 1998;255:139-46. https://doi.org/ 10.1046/j.1432-1327.1998.2550139.x

Masuko T, Minami A, Iwasaki N, Majima T, Nishimura S, Lee YC. Carbohydrate analysis by a phenol-sulfuric acid method in microplate format. Anal Biochem. 2005;339:69-72. https://doi.org/10.1016/j.ab.2004.12.001.

Mosmann T. Rapid colorimetric assay for cellular growth and survival: application to proliferation and cytotoxicity assays. J Immunol Methods. 1983;65:55-63. https://doi.org/10.1016/0022-1759(83)90303-4

Nishimura T, Kometani T, Okada S, Ueno N, Yamamoto T. Inhibitory effects of hydroquinone-alpha-glucoside on melanin synthesis. Yakugaku Zasshi. 1995; 115:626-32. https://doi.org/10.1248/yakushi1947.115.8_626.

Ochanda SO, Faraj AK, Wanyoko JK, Onyango CA, Ruto HK. Extraction and quantification of total polyphenol content in different parts of selected tea cultivars. Am J Plant Sci. 2015;6:1581. https://doi.org/10.4236/ajps.2015.69158.

Park HY, Kosmadaki M, Yaar M, Gilchrest BA. Cellular mechanisms regulating human melanogenesis. Cell Mol Life Sci. 2009;66:1493-506. https://doi.org/10. 1007/s00018-009-8703-8.

Park KT, Kim JK, Hwang D, Yoo Y, Lim YH. Inhibitory effect of mulberroside A and its derivatives on melanogenesis induced by ultraviolet B irradiation. Food Chem Toxicol. 2011;49:3038-45. https://doi.org/10.1016/j.fct.2011.09.008. 
Raper H. The aerobic oxidases. Physiological Reviews. 1928;8:245-82. https://doi. org/10.1152/physrev.1928.8.2.245.

Sanjeewa KA, Park Y-j, Fernando IS, Ann Y-S, Ko C-I, Wang L, Jeon Y-J, Lee W. Soft corals collected from Jeju Island inhibits the a-MSH-induced melanogenesis in B16F10 cells through activation of ERK. Fisheries and Aquatic Sciences. 2018;21:21. doi:https://doi.org/10.1186/s41240-018-0097-9.

Sanjeewa KKA, Kim EA, Son KT, Jeon YJ. Bioactive properties and potentials cosmeceutical applications of phlorotannins isolated from brown seaweeds: a review. J Photochem Photobiol B. 2016;162:100-5. https://doi.org/10.1016/j. jphotobiol.2016.06.027.

Sarangarajan R, Apte SP. The polymerization of melanin: a poorly understood phenomenon with egregious biological implications. Melanoma Res. 2006;16: 3-10. https://doi.org/10.1097/01.cmr.0000195699.35143.df.

Shibata T, Ishimaru K, Kawaguchi S, Yoshikawa H, Hama Y Antioxidant activities of phlorotannins isolated from Japanese Laminariaceae. In: Borowitzka MA Critchley AT, Kraan S, Peters A, Sjøtun K, Notoya M (eds) Nineteenth International Seaweed Symposium: Proceedings of the 19th International Seaweed Symposium, held in Kobe, Japan, 26-31 March, 2007. 2009;vol. Springer Netherlands, Dordrecht, pp 255-261. doi:https://doi.org/10.1007/9781-4020-9619-8_32.

Solano F, Briganti S, Picardo M, Ghanem G. Hypopigmenting agents: an updated review on biological, chemical and clinical aspects. Pigment Cell Res. 2006;19: 550-71. https://doi.org/10.1111/j.1600-0749.2006.00334.x

Tomita Y, Maeda K, Tagami H. Melanocyte-stimulating properties of arachidonic acid metabolites: possible role in postinflammatory pigmentation. Pigment Cell Res. 1992:5:357-61. https://doi.org/10.1111/j.1600-0749.1992.tb00562x.

Vachtenheim J, Borovanský J. "Transcription physiology" of pigment formation in melanocytes: central role of MITF. Exp Dermatol. 2010;19:617-27. https://doi. org/10.1111/j.1600-0625.2009.01053.x.

Vachtenheim J, Novotna H, Ghanem G. Transcriptional repression of the microphthalmia gene in melanoma cells correlates with the unresponsiveness of target genes to ectopic microphthalmia-associated transcription factor. J Invest Dermatol. 2001;117:1505-11. https://doi.org/10. 1046/j.0022-202x.2001.01563.x.

Wang L, Cui YR, Yang H-W, Lee HG, Ko J-Y, Jeon Y-J. A mixture of seaweed extracts and glycosaminoglycans from sea squirts inhibits a-MSH-induced melanogenesis in B16F10 melanoma cells. Fisheries and Aquatic Sciences. 2019;22:11. https://doi.org/10.1186/s41240-019-0126-3.

Wijesinghe WA, Jeon YJ. Enzyme-assistant extraction (EAE) of bioactive components: a useful approach for recovery of industrially important metabolites from seaweeds: a review. Fitoterapia. 2012;83:6-12. https://doi. org/10.1016/j.fitote.2011.10.016.

Yao C, Oh J-h, Oh IG, Park C-h, Chung JH. [6]-Shogaol inhibits melanogenesis in B16 mouse melanoma cells through activation of the ERK pathway. Acta Pharmacol Sin 2013;34:289. doi:https://doi.org/10.1038/aps.2012.134.

Yoon W, Kim M, Koh H, Lee W, Lee N, Hyun C. Effect of Korean red sea cucumber (Stichopus japonicus) on melanogenic protein expression in murine B16 melanoma. Int J Pharmacol. 2010;6:37-42. https://doi.org/10.3923/ijp.2010.37. 42.

\section{Publisher's Note}

Springer Nature remains neutral with regard to jurisdictional claims in published maps and institutional affiliations.

Ready to submit your research? Choose BMC and benefit from:

- fast, convenient online submission

- thorough peer review by experienced researchers in your field

- rapid publication on acceptance

- support for research data, including large and complex data types

- gold Open Access which fosters wider collaboration and increased citations

- maximum visibility for your research: over $100 \mathrm{M}$ website views per year

At BMC, research is always in progress.

Learn more biomedcentral.com/submissions 